\title{
The Effect Of Aloe Vera Decoction On Blood Cholesterol Levels Of Obese Respondents Level I
}

\author{
Kustiasih Lestari ${ }^{1}$, R Sakhnan ${ }^{1}$ \\ Polytechnic Ministry of Health Riau ${ }^{1}$ \\ kustiasih.lestari@pkr.ac.id
}

\begin{tabular}{l} 
Article Info \\
Article history \\
Received date: $2020-05-13$ \\
Revised date: $2020-07-02$ \\
Accepted date: $2020-07-03$ \\
\hline
\end{tabular}

\section{Abstract}

Changes in social trend make many women pursue the career, thus storing breastmilk cannot be avoided if Hypercholesterolemia is a condition in which increased cholesterol levels that exceed normal limits, which have a risk of death of coronary heart disease. Aloe vera is a medicinal plant in Indonesia that is often used by the community as tradisional medicine. Compounds contained in Aloe vera namely phytochemicals that contain phenolics compounds. This study aims to determine the effect of aloe vera boiled water with pre and postest research methods. T-tes statiscal results obtained an average value of cholesterol level before treatment of $206,34 \mathrm{mg} / \mathrm{dL}$ and an average after treatment $182,43 \mathrm{mg} / \mathrm{dL}$, meaning that there are differences in the results of cholesterol levels before and after consuming Aloe vera boiled water. Then it can be concluded that there is a siginicant effect on the provision of Aloe vera boiled water on the reduction of cholesterol levels in obese respondents level with the $p$ value $<0,05$.

Keywords:

Hypercholesterolemia, Cholesterol, Obesity, Aloe Vera

\begin{abstract}
Abstrak
Hiperkolesterolemia adalah keadaan dimana meningkatnya kadar kolesterol yang melebihi batas normal, yang memiliki risiko kematian penyakit jantung koroner. Lidah Buaya (Aloe vera) merupakan tanaman obat di Indonesia yang sering dimanfaatkan oleh masyarakat sebagai obat tradisional. Senyawa yang terkandungan di dalam Lidah Buaya (Aloe vera) yaitu fitokimia yang mengandung senyawa phenolics. Penelitan ini bertujuan untuk mengetahui pengaruh pemberian air rebusan lidah buaya dengan metode penelitian pre and postest. Hasil statistik uji-t didapatkan nilai rata-rata kadar kolesterol sebelum pengobatan sebesar $209,93 \mathrm{mg} / \mathrm{dL}$ dan rata-rata kadar kolesterol sesudah pengobatan sebesar 184,2 mg/dL, artinya ada perbedaan hasil kadar kolesterol sebelum dan sesudah mengkonsumsi air rebusan lidah buaya. Maka dapat disimpulkan adanya pengaruh yang signifikan (bermakna) pada pemberian air rebusan lidah buaya terhadap penurunan kadar kolesterol pada responden obesitas tingkat I dengan nilai $p$ value $<0,05$.
\end{abstract}

Kata Kunci

Hiperkolesterolemia, Kolesterol, Obesitas, Lidah Buaya

\section{PENDAHULUAN}

Hiperkolesterolemia adalah keadaan meningkatnya kadar kolesterol di dalam darah yang melebihi batas normal, yaitu $\geq$ $240 \mathrm{mg} / \mathrm{dl}$. Kenaikan kadar kolesterol ( $\geq 240 \mathrm{mg} / \mathrm{dl}$ ) memiliki risiko kematian penyakit jantung koroner (PJK) tiga kali lipat lebih cepat [12]. Wilayah dengan prevalensi hiperkolesterolemia tertinggi di dunia adalah Eropa (54\%) dan Amerika (48\%). Sedangkan prevalensi terendah adalah wilayah Afrika (23\%) dan Asia tenggara (30\%). Prevalensi hiperkolesterolemia meningkat sesuai dengan pendapatan negara. Masing-masing 
sekitar sepertiga lebih separuh (50\%) penduduk dewasa meningkat kadar kolesterol totalnya[34].

Prevalensi hiperkolesterolemia di Indonesia pada kelompok usia 25-34 tahun adalah $93 \%$ dan meningkat sesuai dengan pertambahan usia hingga 15,5\% pada kelompok usia 55-64 tahun [2]. Berdasarkan hasil Riset Kesehatan Dasar, proporsi penduduk usia $\geq 15$ tahun di Indonesia dengan kadar kolesterol total di atas nilai normal yaitu sebesar 35,9\% [4].

Masyarakat Indonesia sejak zaman dahulu mengenal dan menggunakan tanaman berkhasiat obat sebagai salah satu upaya menanggulangi berbagai masalah kesehatan. Efek samping dari tumbuhan obat ini sangat kecil. Penggunaan tanaman obat untuk penyembuhan penyakit didasarkan pada pengalaman yang secara turuntemurun diwariskan oleh generasi terdahulu kepada generasi berikutnya[30].

Kalangan medis di Indonesia mulai tertarik dengan tumbuhan obat karena tanaman obat jauh lebih murah, mudah didapat dan tidak menimbulkan efek samping sepanjang digunakan sesuai petunjuk[25]. Jenis tanaman obat multiguna yang sangat mudah dimanfaatkan dan berpotensi untuk dikembangkan adalah lidah buaya. Selain dikenal sebagai tumbuhan obat, lidah buaya juga digunakan sebagai bahan kosmetik untuk perawatan kecantikan.

Lidah buaya dikenal sebagai salah satu tanaman obat yang memiliki banyak manfaat kesehatan. Fitokimia (senyawa organik) yang terkandung di dalam lidah buaya terutama senyawa phenolics (flavonoids, saponins, dan terpenoid) karena senyawa tersebut memiliki antioksidan yang tinggi[27]. Flavonoid ditemukan berikatan dengan gula membentuk glikosida yang menyebabkan senyawa ini lebih mudah larut dalam pelarut polar, seperti metanol, etanol, butanol, etil asetat[3].
Kolesterol merupakan lemak darah yang disintesis di hati serta ditemukan dalam sel darah merah, membran sel, dan otot. Kirakira sebanyak $70 \% \quad$ kolesterol diseterifikasikan (dikombinasi dengan asam lemak), serta $30 \%$ dalam bentuk bebas. Kolesterol digunakan tubuh untuk membentuk garam empedu sebagai fasilitator pencernaan lemak dan untuk pembentukan hormon oleh kelenjar adrenal, ovarium dan testis. Kolesterol digunakan sebagai indikator penyakit arteri koroner dan aterosklerosis. Hiperkolesterolemia menyebabkan penumpukan plak di arteri koroner sehingga dapat menyebabkan $\mathrm{MCl}[15]$.

\section{METODE}

Jenis penelitian yang digunakan adalah Experimental dengan menggunakan one group pre and post test design yaitu suatu penelitian dengan melakukan kegiatan percobaan yang bertujuan untuk mengetahui pengaruh perlakuan atau perbedaan perubahan terhadap kelompok yang diberikan perlakuan .

Populasi dalam penelitian ini adalah semua responden penderita obesitas tingkat I yang berjumlah 30 orang Rumbai di kawasan kampus Universitas Abdurrab Pekanbaru dan di daerah Limbungan. Analisis data menggunakan analisa bivariat uji $t$ yang dilakukan untuk melihat pengaruh air rebusan lidah buaya pada kolesterol penderita obesitas tingkat I dengan menggunakan microsoft exel.

\section{Hasil Penelitian}

\section{Karakteristik Responden}

Responden dalam penelitian ini adalah penderita kolesterol obesitas tingkat I dengan IMT 25,1 - 29,9 di Kampus Universitas Abdurrab sebanyak 30 orang responden. Penelitian ini dilakukan pada bulan Mei - Juli 2019. Data mengenai 
gambaran umum karakteristik subyek penelitian terdapat pada tabel 1 :

Tabel 1. Karakteristik Responden Berdasarkan Jenis

Kelamin

\begin{tabular}{ccc}
\hline Karakteristik & Responden & Persentase (\%) \\
\hline Laki - laki & 9 & 30 \\
Perempuan & 21 & 70 \\
\hline Jumlah & 30 & 100
\end{tabular}

Berdasarkan tabel 1 dapat dilihat bahwa jumlah responden berdasarkan jenis kelamin terdiri dari 9 orang responden laki-laki (20\%) dan 21 orang responden perempuan (70\%). Penelitian tersebut dapat diketahui bahwa sebagian penderita kolesterol obesitas tingkat I lebih banyak perempuan yang dimulai dari masa lanjut usia awal.

Tabel 2. Distribusi Frekuensi Berdasarkan Usia Pasien

\begin{tabular}{ccc}
\multicolumn{3}{c}{ Obesitas Tingkat I } \\
\hline Usia & Responden & Persentase (\%) \\
\hline $30-40$ & 18 & 60 \\
$40-50$ & 9 & 30 \\
$>50$ & 3 & 10 \\
\hline Jumlah & 30 & 100
\end{tabular}

Berdasarkan tabel 2 dapat dilihat bahwa jumlah responden berusia $30-40$ tahun terdiri dari 18 orang (60\%), berusia 40 50 tahun terdiri dari 9 orang $(30 \%)$ dan berusia $>50$ tahun terdiri dari 3 orang $(10 \%)$. Penelitian tersebut dapat diketahui bahwa sebagian penderita kolesterol obesitas tingkat I terdapat pada usia 30 40 tahun berjumlah 18 orang.

Tabel 3. Tabel Kadar Kolesterol Pasien Obesitas

Tingkat I Sebelum dan Sesudah Pemberian Air Rebusan Lidah Buaya

\begin{tabular}{ccccc}
\hline No & Inisial & $\begin{array}{c}\text { Kadar } \\
\text { Sebelum } \\
(\mathrm{mg} / \mathrm{dL})\end{array}$ & $\begin{array}{c}\text { Kadar } \\
\text { Sesudah } \\
(\mathrm{mg} / \mathrm{dL})\end{array}$ & Ket \\
\hline & $\mathrm{RN}$ & 191 & 183 & Menurun \\
$:$ & $\mathrm{YN}$ & 222 & 168 & Menurun \\
$\mathrm{RY}$ & 228 & 195 & Menurun \\
$\mathrm{AR}$ & 208 & 159 & Menurun \\
\hline
\end{tabular}

\begin{tabular}{|c|c|c|c|c|}
\hline ! & SA & 205 & 194 & Menurun \\
\hline । & ZK & 207 & 151 & Menurun \\
\hline ; & SW & 214 & 192 & Menurun \\
\hline i & $\mathrm{JH}$ & 197 & 171 & Menurun \\
\hline ' & RS & 190 & 166 & Menurun \\
\hline & ED & 193 & 163 & Menurun \\
\hline & $\mathrm{EL}$ & 188 & 141 & Menurun \\
\hline & DR & 255 & 245 & Menurun \\
\hline & RS & 215 & 184 & Menurun \\
\hline & $\mathrm{SH}$ & 238 & 202 & Menurun \\
\hline & $\mathrm{NH}$ & 191 & 175 & Menurun \\
\hline & $E M$ & 233 & 218 & Menurun \\
\hline & $\mathrm{RR}$ & 218 & 194 & Menurun \\
\hline & $\mathrm{HH}$ & 197 & 194 & Menurun \\
\hline & WS & 199 & 172 & Menurun \\
\hline : & RA & 160 & 153 & Menurun \\
\hline : & EN & 212 & 203 & Menurun \\
\hline : & WN & 230 & 219 & Menurun \\
\hline : & $E M$ & 204 & 201 & Menurun \\
\hline : & AN & 216 & 180 & Menurun \\
\hline : & IA & 215 & 170 & Menurun \\
\hline : & $\mathrm{JN}$ & 214 & 185 & Menurun \\
\hline : & $\mathrm{HM}$ & 215 & 195 & Menurun \\
\hline : & $\mathrm{JH}$ & 225 & 199 & Menurun \\
\hline : & KA & 252 & 208 & Menurun \\
\hline ; & $\mathrm{RN}$ & 215 & 196 & Menurun \\
\hline & Jumlah & \multicolumn{3}{|c|}{5526} \\
\hline & & \multicolumn{3}{|l|}{6298} \\
\hline & $\begin{array}{l}\text { Rata - } \\
\text { rata }\end{array}$ & 209,93 & 184,2 & \\
\hline
\end{tabular}

Tabel 3 menunjukkan nilai rata - rata kadar kolesterol pasien obesitas tingkat I sebelum pemberian air rebusan lidah 209,93 mg/dL. Nilai rata-rata kadar kolesterol pasien obesitas tingkat I setelah pemberian air rebusan lidah buaya selama 30 hari 184,2 $\mathrm{mg} / \mathrm{dL}$. Ditinjau dari kedua data diatas terlihat ada perbedaan. Perbedaan tersebut signifikan atau tidak perlu dilakukan perhitungan statistik dengan menggunakan uji T berpasangan.

\section{Analisa Uji $\boldsymbol{t}$ dependent}

Analisa uji $t$ dependent responden meliputi kadar kolesterol obesitas tingkat I sebelum pengobatan dan sesudah pengobatan selama 14 hari. 
Statistik Sampel Uji † Dependent Tabel 4. Hasil Uji Statistik Sampel Dependent

\begin{tabular}{cccc}
\hline $\begin{array}{c}\text { Pemberian } \\
\text { Lid Rebusan }\end{array}$ & $\begin{array}{c}\text { Rerata } \\
\text { Kadar } \\
\text { Kolesterol } \\
(\mathrm{mg} / \mathrm{dL})\end{array}$ & Jumlah & $\begin{array}{c}\text { Standar } \\
\text { Deviasi }\end{array}$ \\
\hline Sebelum & 209,93 & 30 & 21,39 \\
Sesudah & 184,2 & 30 & 24,41 \\
\hline
\end{tabular}

Tabel 4. Menunjukkan bahwa nilai rerata pemeriksaan kadar kolesterol obesitas tingkat I pada sampel sebelum pengobatan sebesar 209,93 mg/dL dengan standar deviasi 21,39 , sedangkan hasil rerata kadar kolesterol obesitas tingkat I sesudah pengobatan selama 30 hari $184,2 \mathrm{mg} / \mathrm{dL}$ dengan standar deviasi 24,41.

Tabel 5. Uji Sampel Berpasangan

\begin{tabular}{ccc}
\hline Nilai $t$ & Df & $\begin{array}{c}\text { Signfikan }(2- \\
\text { tailed) }\end{array}$ \\
9,26 & 29 & 0,000 \\
\hline
\end{tabular}

Hasil dari statistik uji-t didapatkan $\dagger$ hitung $>+$ tabel, maka $\mathrm{H}_{0}$ ditolak, artinya ada perbedaan hasil kadar kolesterol obesitas tingkat I sebelum dan sesudah pemberian air rebusan lidah buaya selama 30 hari. Dikuatkan dengan jumlah signifikan (2-tailed) $=0,000<0,05$, maka disimpulkan bahwa ada pengaruh yang signfikan terhadap pemberian air rebusan lidah buaya terhadap kadar kolesterol obesitas tingkat I.

\section{Pembahasan}

Tabel 1 dapat dilihat bahwa jumlah responden berdasarkan jenis kelamin terdiri dari 9 orang responden laki-laki (30\%) dan 21 orang responden perempuan (70\%). Penelitian tersebut dapat diketahui bahwa sebagian penderita kolesterol obesitas tingkat I lebih banyak perempuan yang dimulai dari masa lanjut usia awal. Menurut penelitian[28], mengatakan ada faktor lain yang juga turut mempengaruhi kadar kolesterol normal dan tinggi pada penelitian ini yaitu usia, terutama pada wanita. Wanita mempunyai hormon estrogen yang menjadi faktor determinan terhadap perubahan profil lipid darah. Terutama pada penelitian ini, seluruh responden yang masih menstruasi. Peran estrogen dalam meningkatkan kolesterol hampir mencapai $15 \%$ dari produksi dan pengangkutan kolesterol. Kadar kolesterol menurut peneliti sendiri dalam hal ini berhubungan langsung dengan aktivitas fisik dan kebiasaan tidak merokok terutama responden pria.

Tabel 2 dapat dilihat bahwa jumlah responden berusia $30-40$ tahun terdiri dari 18 orang $(60 \%)$, berusia 40 - 50 tahun terdiri dari 9 orang $(30 \%)$ dan berusia $>50$ tahun terdiri dari 6 orang (10\%). Penelitian tersebut dapat diketahui bahwa sebagian penderita kolesterol obesitas tingkat I terdapat pada usia 30 - 40 tahun berjumlah 18 orang. Menurut penelitian Ujiani, 2015[21], menunjukkan bahwa penderita obesitas terbanyak pada usia 51 - 60 tahun, ini menggambarkan semakin bertambahnya usia akan berisiko mengalami obesitas, karena terjadi akumulasi lemak secara berlebihan di dalam tubuh, yang didukung oleh perubahan pola makan yang tadinya tinggi karbohidrat, tinggi serat dan rendah lemak berubah ke pola makan baru yang rendah karbohidrat, rendah serat, dan tinggi lemak, sehingga menggeser mutu makanan ke arah yang tidak seimbang. 
Karena proses penuaan, metabolisme tubuh secara alami akan melambat dan mobilitas yang rendah mempercepat proses penggantian massa otot dengan lemak tubuh.

Indeks massa tubuh di atas normal $(25,1)$ pada analisis bivariat cenderung memiliki risiko kadar kolesterol lebih tinggi $30-39 \%$ sedangkan pada analisis multivariat memiliki risiko 22 - 27\% lebih tinggi dibandingkan referensi. Hasil analisis bivariat dan multivariat menunjukkan semakin bertambah usia semakin tinggi risiko terkena hiperkolesterolemia. Penelitian lain mempunyai hasil serupa, kadar kolesterol meningkat seiring dengan pertambahan usia. Hal serupa tampak pada indeks massa tubuh, yaitu pada golongan kelebihan berat badan tingkat ringan atau sedang dengan nilai IMT di atas 25,1 mempunyai kecenderungan kadar kolesterol 30\% lebih tinggi dibandngkan dengan responden yang mempunyai berat badan normal. Indeks massa tubuh mencerminkan gambaran tubuh seseorang. Semakin bertambah usia perlu diwaspadai risiko terkena hiperkolesterolemia dengan menghindari beberapa faktor risiko seperti memelihara indeks massa tubuh pada batas normal yaitu 18,5 s./d 25,0[18].

Tabel 3 menunjukkan nilai rata-rata kadar kolesterol pasien obesitas tingkat I sebelum pemberian air rebusan lidah buaya 209,34 $\mathrm{mg} / \mathrm{dL}$. Nilai rata-rata kadar kolesterol pasien obesitas tingkat I setelah pemberian air rebusan lidah buaya selama 30 hari $184,2 \mathrm{mg} / \mathrm{dL}$. Ditinjau dari kedua data diatas terlihat ada perbedaan. Perbedaan tersebut signifikan atau tidak perlu dilakukan perhitungan statistik dengan menggunakan uji T berpasangan. Penelitian yang dilakukan oleh Subbiah Rajasekaran di India menunjukkan bahwa Aloe vera dapat menurunkan profil lipid dalam darah dan juga menurunkan kadar glukosa dalam darah secara signifikan. Kandungan Aloe vera yang diduga dapat menurunkan kadar kolesterol adalah serat yang larut dalam air yaitu antioksidan, flavonoid, niavin dan vitamin C. Flavonoid merupakan salah satu kelompok senyawa fenolik yang banyak terdapat pada jaringan tanaman dapat berperan sebagai antioksidan. Aktivitas antioksidatif flavonoid bersumber pada kemampuan mendonasikan atom hidrogen nya atau melalui kemampuannya mengkelat logam, berada dalam bentuk glukosida.

Menurut teori (Sianipar dan Isnawati, 2012)[28], mengatakan lidah buaya dapat menurunkan kadar kolesterol secara bermakna karena mengandung beberapa bahan aktif seperti niacin (vitamin B3), yang dapat menurunkan kadar VLDL, sehingga kadar kolesterol HDL dan kadar kolesterol LDL juga turun. Vitamin $C$ yang mempunyai efek samping membantu hidroksilasi dalam pembentukan asam empedu sehingga meningkatkan ekskresi kolesterol. Vitamin E dan vitamn A bertinfdak sebagai antioksidan yang melindungi kolesterol LDL dari oksidasi.

\section{SIMPULAN}

Berdasarkan hasil penelitian tentang pengaruh pemberian air rebusan lidah buaya terhadap kadar kolesterol obesitas tingkat I dapat disimpulkan bahwa dari 
statistik uji-t didapatkan $t$ hitung $>$ t tabel dan nilai $p$ value (sgnifikan) $<0.05$. Mayoritas kadar kolesterol sebelum pemberian dan setelah pemberian air rebusan lidah buaya mengalami penurunan kadar kolesterol yang signifikan. Hal ini membuktikan bahwa adanya pengaruh yang signifikan (bermakna) pada pemberian air rebusan lidah buaya terhadap penurunan kadar kolesterol pada responden obesitas tingkat I.

\section{UCAPAN TERIMA KASIH}

Berisi ucapan terima kasih kepada lembaga pemberi dana/individu, dan atau yang telah membantu dalam pelaksanaan penelitian, serta lembaga afiliasi penulis. Penulisan menggunakan Tw Cen MT, 12, spasi 1.

\section{DAFTAR PUSTAKA}

[1] Adiwiyoto, A. Kolesterol Yang Perlu Anda Ketahui. Jakarta: Kesaint Blanc. 2004.

[2] Aurora, R.G., Sinambela, A., dan Noviyanti, C.H. 2012. Peran Konseling Berkelanjutan pada Penanganan Pasien Hiperkolesterolemia. J. Indo Med Assoc, Volum: 62, Nomor: 5, Mei 2012.

[3] Bangun. Terapi Jus Dan Ramuan Tradisional untuk Kolesterol. Jakarta: AgroMedia. 2008.

[4] Baron, D.N. Kapita Selekta Patologi Klinik Edisi 4. Jakarta: ECG. 2002.

[5] Fikri, F. Bahaya Kolesterol Memahami, Mendeteksi dan Mengontrol Kolesterol. Yogyakarta: Kata Hati. 2014.

[6] Freitag, H. Bebas Obesitas Tanpa Diet Menyiksa. Yogyakarta: MedPress. 2010.
[7] Furnawanthi, I. Khasiat dan Manfaat Lidah Buaya Si Tanaman Ajaib. Jakarta: AgroMedia Pustaka. 2002.

[8] Gandasoebrata, R. Penuntun Laboratorium Klinik. Jakarta: Dian Rakyat. 2010.

[9] Ginanjar, G. Obesitas Pada Anak. Jakarta: Pustaka Makmur. 2009.

[10] Handayani, S. Lidah Buaya \& Kegunaannya. Jakarta: IndoBook Citra Media. 2008.

[11] Hanani, E. Analisis Fitokimia. Jakarta: Penerbit Buku Kedokteran. EGC. 2015.

[12] Harrison. Prinsip-Prinsip Ilmu Penyakit Dalam. Jakarta: Penerbit Buku Kedokteran. ECG. 2000.

[13] H. R., Hasdianah. Mengenal Diabetes Mellitus Pada Orang Dewasa dan Anakanak Dengan Solusi Herbal. Yogyakarta: Nuha Medika. 2012.

[14] Iman, S. Serangan Jantung dan Stroke Hubungannya dengan Lemak \& Kolesterol. Jakarta: PT Gramedia Pustaka Utama. 2004.

[15] Kee, Joyce LeFever. Pedoman Pemeriksaan Laboratorium \& Diagnostik. Jakarta: Penerbit Buku Kedokteran. EGC. 2007.

[16] Kardinan,. A dan Ruhnayat,. A. Budi Daya Tanaman Obat Secara Organik. PT. Jakarta: AgroMedia Pustaka. 2003.

[17] Mulyanto, D. Panjang Umur Dengan Kontrol Kolesterol \& Asam Urat. Jakarta: Cahaya Atma. 2012.

[18] Nelson, RH. Hyperlipidemia as a Risk Factor for Cardiovascular Disease. Prim Care. Author manuscript. 40(1 26 195-211. 2013. 
[19] Nilawati, S. Care Your Self Kolestrol,. Yogyakarta: Penerbit C.V Andi Offset. 2008.

[20] Notoatmodjo, S. Metodologi Penelitian Kesehatan. Jakarta: Rineka Cipta. 2012.

[21] Proverawati, A. Obesitas dan Gangguan Perilaku Makan Pada Remaja. Yogyakarta: NuhaMedika. 2010.

[22] Purwadaksi, R. Memanfaatkan Perkarangan Untuk Tanaman Obat Kelvarga. Jakarta: Redaksi Agromedia. Hal: 23-26. 2007.

[23] Rajasekaran, S. Beneficial Effects of Aloe vera Leaf Ge Extract on Lipid Profile Status in Rats with Streptozotocin Diabetis. Clinical and Experimental Pharmacology and Physiology, Tamil nadu, India. 2006.

[24] Riset Kesehatan Dasar (Riskesdas). Pokok-Pokok Hasil Riset Kesehatan Dasar Provinsi Riau. Jakarta: Badan Penelitian dan Pengembangan Kesehatan Kementerian Kesehatan RI. 2013.

[25] Santoso, B. Tumbuhan Obat. Penebar Swadaya, Jakarta: Hal: 71-76. 2008.

[26] Setiati, E. Bahaya Kolesterol, Mengenal, Mencegah dan Menanggulangi Kolesterol. Yogyakarta: Dokter Books, hal: $31-32,36.2009$.

[27] Sharrif, M. M., \& Verma, S. K. Aloe Vera their chemical composition and applications: A review. Int J Biol Med Res, 2 (1), 466-471. 2011.

[28] Sianipar, Y., \& Isnawati, M. Pengaruh Pemberian Jus Lidah Buaya Terhadap Kadar Kolesterol LDL dan HDL. Semarang: Program Studi llmu Gizi Fakultas Kedokteran Universitas Diponegoro. 2012.
[29] Sukeksi, A., dan Anggraini H. Kadar Kolesterol Darah Pada Penderita Obesitas Di Kelurahan Korpri Sambiroto Semarang. Jurnal Kesehatan Unimus. Vol. 2 No. 2. 2009.

[30] Utami, P. Buku Pintar Tanaman Obat. Jakarta: PT. AgroMedia Pustaka. 2008.

[31] Wahiono, E. Mengebunkan Lidah Buaya Secara Intensif. Jakarta: PT. AgroMedia Pustaka. 2002.

[32] Wijayanti, D. Analisa Faktor Penyebab Obesitas dan Cara Mengatasi Obesitas Pada Remaja Putri. Skripsi tidak diterbitkan. Fakultas Ilmu Keolahragaan Universitas Negeri Semarang. 2013.

[33] Wiryowidagdo, $S$, Sitanggang, $M$. Tanaman Obat Untuk Penyakit Jantung, Darah Tinggi, dan Kolesterol. Jakarta: PT. Agro Media Pustaka. 2002.

[34] WHO. Global Atlas on CardiovaskularDisease Prevention and Control. Medis. S, Pustaka, Norrving B. 2011.

[35] Yani, M. Mengendalikan Kadar Kolesterol Pada Hiperkolesterolemia. Jurnal Olahraga Prestasi. Vol 11 . No 2. 2015.

[36] Yatim, F. Kendalikan Obesitas dan Diabetes. Jakarta: Sarang Pustaka Prima. 